\title{
Vamos brincar? Material lúdico-pedagógico voltado para crianças cegas e de baixa visão em fase de escolarização
}

Let's play? Ludo-pedagogical material for blind and visually impaired children at schoolling age

JACOB, Elizabeth Motta; Doutor; UFRJ

e.jacob@uol.com.br

CARDOSO, Fernanda de Abreu; Doutor; UFRJ

fernandadsg@gmail.com

\section{Resumo}

Neste artigo apresentamos a proposta, o desenvolvimento e os resultados alcançados até o momento pelo projeto de extensão universitária Pleno Sentido. Desenvolvido no âmbito de um curso de Comunicação Visual - Design em parceria com o Instituto Benjamin Constant, o objetivo do projeto é contribuir, através do Design, para a criação de materiais educativos voltados para o público deficiente visual em fase de escolarização. O projeto visa suprir a carência de material didático, lúdico, estético e de apelo sensorial voltado para o processo de aprendizagem de crianças cegas e de baixa visão, ou seja, pretendemos usar o Design como ferramenta para promover a inclusão social. Nosso trabalho consiste na produção de livros-objeto, jogos educativos e produtos que possam servir de material de apoio a professores na transmissão de saberes de forma dinâmica, lúdica e efetiva de forma a permitir a plena inclusão desta parcela significativa de cidadãos brasileiros em nossa sociedade.

Palavras Chave: Design inclusivo; material grafo-tátil; deficiência visual

\begin{abstract}
This article presents the proposal, development and results achieved so far by the University extension project Full Sense. Developed in the context of a Visual Communication - Design graduation course in partnership with the Benjamin Constant Institute, the project 's goal is to contribute to the creation of educational material aimed at the visually impaired children at schooling phase through Design. The project aims to supply the lack of didactic, playful, aesthetic and with sensory appeal material for the blind and low vision children's learning process, that is, we intend to use Design as a tool to promote social inclusion. Our work consists in the production of object books, educational games and products that can be used as support material for teachers. Through these objects, knowledge would be transmitted in a more dynamic, playful and effective way in order to allow the full inclusion of this significant portion of Brazilian citizens in our society.
\end{abstract}

Keywords: Inclusive design, graphic tactile material, visually impaired 


\section{Introdução}

Visamos apresentar aqui parte de nossos estudos desenvolvidos no sentido de contribuir para a produção de material didático, lúdico, estético e de forte apelo sensorial para auxiliar no processo de aprendizagem de crianças cegas e de baixa visão. Este trabalho apresenta alguns resultados do projeto de extensão Pleno Sentido, cujo objetivo é contribuir para a criação de materiais educativos voltados para o público deficiente visual. Nosso trabalho consiste na produção de livros-objeto, jogos educativos e produtos que possam servir de material de apoio a professores na transmissão de saberes de forma dinâmica, lúdica e efetiva de forma a permitir a plena inclusão desta parcela significativa de cidadãos brasileiros em nossa sociedade. Exploramos neste trabalho a percepção de mundo da criança cega ou de baixa visão criando narrativas a partir de suas vivências e formas de perceber o mundo. Trabalhamos com projetos de objetos que evoquem os sentidos auditivo, tátil, olfativo, gustativo e, porque não visual, de forma a despertar a sensorialidade no relacionamento com o artefato e atrair o público vidente para partilhar a experiência.

Diante da percepção da carência e limitação de material voltado para o público em tela, observamos uma oportunidade de atuação do Design como ferramenta de inclusão social. Entendemos aqui "carência" em seu sentido amplo, ou seja, percebemos que há uma escassez de trabalhos que ofereçam soluções projetuais com foco neste perfil de usuário, uma insuficiência de material inclusivo no sentido de propiciar interação entre cegos, baixa visão e videntes, uma carência em termos de inclusão social voltado ao franco desenvolvimento da pessoa deficiente visual em termos de cidadania.

A demanda por projetos de extensão surgiu da Universidade Federal do Rio de Janeiro que entende a aplicação dos conhecimentos nela desenvolvidos como sua responsabilidade social. As autoras deste artigo, docentes desta Universidade, se sensibilizaram com esta proposta e empreenderam uma jornada no sentido de estabelecer vínculos institucionais que permitisse alcançar resultados eficazes com o Design. Assim juntamos a função social da universidade com a função social do Design em um único projeto, o Pleno Sentido ${ }^{1}$ e há três anos estamos trabalhando integrando projetos de conclusão de curso e atividades extensionistas às demandas do Instituto Benjamim Constant - RJ, doravante IBC.

Nossa proposta é unir as nossas expertises em Design com as expertises dos profissionais do instituto no atendimento de crianças cegas e de baixa visão e aproximar nossos alunos da UFRJ de uma população excluída tanto socialmente quanto pelo mercado editorial, criando empatia e capacitação na criação de material especializado. Deste modo temos desenvolvido livros e brinquedos com este fim.

O público alvo deste projeto são crianças da pré-escola e do ensino fundamental do Instituto Benjamim Constant que são em sua maioria, crianças de famílias de baixa renda necessitando de apoio em todos os níveis para seu pleno desenvolvimento e inserção social. O quadro em que se encontram essas crianças merece especial atenção na medida em que todos os esforços devem ser feitos para a sua plena capacitação. Muitas dessas crianças moram em municípios distantes, o que implica num investimento muito grande de suas famílias que devem se deslocar com a criança todos os dias no sentido de obter assistência no Instituto. Entendemos então, que criar meios

\footnotetext{
${ }^{1}$ O Projeto Pleno Sentido foi firmado através de acordo institucional entre a Universidade Federal do Rio de Janeiro e o Instituto Benjamim Constant- RJ visando a produção de material grafo-tátil para auxiliar o desenvolvimento de crianças cegas e de baixa visão em seus processos de aprendizagem.
} 
facilitadores para o pleno desenvolvimento destas crianças é uma importante função do designer e da Universidade que, por meio de pesquisas como a nossa, tem meios de desenvolver ferramentas adequadas para facilitar a instrumentalização e empoderamento dessas crianças.

Consideramos importante esclarecer quem é nosso público alvo e como ele se constitui: deficiente visual é considerado aquele que tem perda parcial ou total da visão de ambos os olhos. Deste modo consideram-se cegas as pessoas que tem perda total ou capacidade ínfima de enxergar, para esses há a necessidade do sistema Braille $^{2}$ para leitura e escrita. Já aqueles considerados de baixa visão possuem acuidade visual reduzida e conseguem ver imagens, identificar letras e sinais ampliados ou com o apoio de recursos óticos. Apesar de ter uma população de mais de 6.5 milhões de deficientes visuais, dentre estes por volta de 580 mil cegos, a produção de material didático, pedagógico e de entretenimento no Brasil, é muito pequena o que faz com que a integração destes cidadãos na sociedade seja prejudicada.

Sentimos, portanto, grande necessidade em estimular a interação e a inclusão do deficiente visual na sociedade de forma plena. A educação é uma das chaves neste processo e acreditamos que o acesso à informação é fundamental. Pretendemos através do Design, promover a inclusão cultural e social das pessoas com deficiência visual, criando objetos com este objetivo. Estamos alinhados com a corrente de Disability Studies ${ }^{3}$, em que se defende uma integração social do indivíduo não vidente através da adequação e adaptação dos conteúdos visuais para este público e não através da tentativa de adaptação dos deficientes visuais à cultura visual dos videntes.

Nossa sociedade tem se tornado cada vez mais uma sociedade de imagens em que o foco no sentido da visão tem sido especialmente desenvolvido. Percebe-se hoje uma atribuição à produção da emoção estética centrada nos aspectos visuais. Esquece-se que o verdadeiro sentido de estética consiste na convocação dos sentidos e que a visão é apenas um deles. No que concerne aos livros, por exemplo, nosso trabalho reside em elaborar projetos gráficos que proporcionem a interatividade entre os públicos estimulando os órgãos sensitivos dos leitores, através de elementos sensoriais.

Cabe lembrar, como nos diz MARKS (2000, p.139) que os sentidos são formados em um contexto social. A autora destaca o pensamento de Marx que acreditava que a alienação do indivíduo na modernidade estaria para além das dimensões do trabalho uma vez que ela se imprime em relação a seu próprio corpo e seus sentidos. Ela afirma ainda que a cultura capitalista aliena os sentidos que implicam em aproximação maior, tais como o olfato, enquanto valoriza o sentido da visão até que este assuma o caráter de uma arma. Isto porque a visão é o sentido que permite uma percepção mais ampla e distanciada do que está ocorrendo enquanto todos os outros solicitam maior aproximação ou contato. Isto fica igualmente muito evidente no que concerne ao tato. Este sentido implica em proximidade e presença. Acostumados, cada vez mais as comunicações mediadas virtualmente nos distanciamos um dos outros e isso é um grande dificultador na inclusão da criança cega.

\footnotetext{
${ }^{2} \mathrm{O}$ sistema Braille é um processo de escrita e leitura baseado em 64 símbolos em relevo, resultantes da combinação de até seis pontos dispostos em duas colunas de três pontos cada. Pode-se fazer a representação tanto de letras, como algarismos e sinais de pontuação. Ele é utilizado por pessoas cegas e a leitura é feita da esquerda para a direita, ao toque de uma ou duas mãos ao mesmo tempo.

${ }^{3}$ Ver: VALENTE, D. Imagens que comunicam aos dedos: a fabricação de desenhos táteis para pessoas cegas. In: Anais do $17^{\circ}$ Encontro Nacional da Associação Nacional de Pesquisadores em Artes Plásticas. Panorama da Pesquisa em Artes Visuais, 2008.
} 
Assim, de forma a restaurar os sentidos do corpo e explorar suas potencialidades fazemos nossos produtos com textos no sistema Braille e em tinta e incluímos texturas, cheiros, sabores, sons, buscando permitir o compartilhamento do livro entre os leitores cegos e videntes, integrando o corpo em todo o processo de leitura fornecendo o alcance do conhecimento cultural para todos os que vivem em sociedade. Deste modo pensamos nossos livros, jogos, brinquedos e atividades inclusivas como elementos facilitadores na integração da criança cega e de baixa visão no contexto de suas famílias e ambiente social.

A leitura é um modo de abrir os horizontes de um indivíduo e a incorporação de elementos que estimulem os diversos sentidos neste ato integra o corpo do leitor de modo ativo na apreensão do conhecimento. Entendemos que o desenvolvimento dos sentidos da audição, tato, olfato e paladar são importantes no desenvolvimento da percepção da criança cega de forma a auxiliar o entendimento mais integralizado do seu próprio corpo, sua integração com o espaço físico que a circunda e seu pertencimento social.

A possibilidade de participar de atividades em família e com amigos videntes através destes materiais lúdicos e inclusivos abre possibilidades da criança cega e de baixa visão se desenvolver física e emocionalmente na medida em que se reforçam os laços afetivos e os mecanismos de acolhimento. Entendemos, portanto, o Design como uma ferramenta muito importante na geração de afetos e para a integração entre diferentes agentes sociais.

O objetivo da arte, com os meios do material, é arrancar o percepto das percepções do objeto e dos estados de um sujeito percipiente, arrancar o afeto das afecções, como passagem de um estado a outro. Extrair um bloco de sensações um puro ser de sensações. (DELEUZE, 2005, p.217)

Neste sentido, os objetos devem ampliar as possibilidades de contato, de experimentação e provocar vivências que integrem os agentes que os utilizam. Se estamos preocupados com o desenvolvimento da criança em sua família e entorno social, estamos também inquietas com a sua integração e desenvolvimento no meio escolar.

Este material está sendo pensado como apoio pedagógico de uso em e fora da sala de aula. Sua utilização visa atender a demanda dos professores do IBC sendo ao mesmo tempo lúdico e instigante a nível didático e/ou paradidático. No que cabe aos brinquedos, visamos auxiliar em assuntos para os quais material específico se faça necessário na transmissão de diferentes saberes.

Neste sentido, e foi dito anteriormente, a parceria com o IBC e suas expertises é fundamental. O IBC se constitui como centro de referência, a nível nacional, para questões da deficiência visual. Ele tem como meta a capacitação de crianças e adolescentes com deficiência visual tendo como campo de ação a escolarização de seu público alvo, a reabilitação de pessoas que perderam a visão, a realização de atendimento oftalmológico para a população, além da criação e produção de material especializado, seja na forma de impressos em Braille, publicações científicas ou qualquer outro tipo de material voltado para o atendimento da população em tela. Além disso, o IBC dá suporte a escolas e instituições que atendam deficientes visuais.

Para efetivar esta contribuição resolvemos trabalhar no sentido de produzir material grafotátil, lúdico para apoio de aprendizagem de crianças cegas, nos aproximar dos professores do instituto, entender as carências e desenvolver material de apelo sensorial ampliando a capacidade dos cegos e os de baixa visão de lidar com os sentidos, aprender de forma lúdica e atender a demandas específicas de ensino-aprendizagem 
No caso da criança privada do sentido da visão os recursos didáticos devem ser desenvolvidos de forma particular. São considerados recursos didáticos os recursos físicos com objetivo de auxiliar a educação, facilitando e tornando a aprendizagem mais eficiente. No processo de educação de crianças com deficiência visual, estes recursos são de extrema importância pois como toda criança, elas precisam de motivação para a aprendizagem; estes recursos também podem suprir lacunas na aquisição de informações e ainda, o manuseio de diferentes materiais possibilita o treinamento da percepção tátil, facilitando a discriminação de detalhes e suscitando a realização de movimentos delicados com os dedos, conforme relatam Cerqueira e Ferreira (1996).

\section{Metodologia do projeto}

Neste artigo apresentamos 5 trabalhos desenvolvidos pelos discentes do curso Comunicação Visual - Design no âmbito do projeto de extensão Pleno Sentido. Cada uma dessas propostas de trabalho teve como ponto de partida a observação de necessidades do público alvo. Alguns deles se tornaram trabalhos de conclusão de curso, outros, pesquisas de alunos bolsistas de extensão, procuraram atender demandas específicas apresentadas pelos docentes do IBC. Todos os trabalhos tinham como objetivo a elaboração de um produto grafo-tátil com enfoque lúdico e pedagógico e por conta de suas especificidades particulares, cada um teve seus próprios caminhos/percursos metodológicos. Por isso, descreveremos brevemente etapas gerais dos processos adotados no projeto de forma mais ampla.

Inicialmente foi realizada pesquisa bibliográfica sobre a percepção de cegos, a produção de objetos grafo-táteis para este público, recursos e possibilidades técnicas de produção, além de materiais adequados a serem usados nos projetos.

Em seguida foram realizadas visitas ao Instituto Benjamim Constant, onde conhecemos o espaço físico do Instituto. Visitamos as salas de aula, teatro, espaços de lazer e convívio dos alunos; tivemos acesso à gráfica do Instituto onde pudemos conhecer in loco o processo de impressão em Braille, o uso do Thermoform ${ }^{4}$ e as publicações produzidas neste local; exploramos o espaço de exposições e acervo de objetos usados para o ensino das aulas de biologia; visitamos o setor de gravação de áudio-livros; conhecemos o acervo da biblioteca e tivemos contato com professores e técnicos do Instituto.

Com as visitas foi possível ter o primeiro contato com as demandas do Instituto e identificar os recursos e as limitações que se apresentavam para o trabalho. Foram definidos os usos dos recursos do IBC, como o maquinário da gráfica para a impressão em Braille e em Thermoform e como seria a entrada em sala de aula e o contato com os alunos. As conversas iniciais com os técnicos e professores foram fundamentais para conhecermos este novo universo. Nesta etapa do trabalho os alunos da UFRJ, bolsistas e não bolsistas, estiverem em contato com as professoras do IBC e em realizaram um observação participativa em sala de aula. Deste modo a integração entre suas diversas necessidades e inquietudes vieram a dialogar com as das professoras e alunos, havendo assim uma construção de conhecimento coletivo. Nesta etapa foi possível fortalecer o vínculo com a Instituição e houve uma integração bastante ampliada com os docentes, antes bastante refratários à nossa presença no instituto. Progressivamente, tivemos o reconhecimento de nosso trabalho e os docentes começaram a nos demandar suporte.

\footnotetext{
${ }^{4}$ Processo de moldagem de material plástico através de alta temperatura, que permite produzir texturas e imagens em relevo, usado em diversas publicações do Instituto.
} 
Por solicitação das professoras, estamos desenvolvendo no momento um jogo de batalha naval para apoio ao ensino das coordenadas ortogonais para as aulas de matemática e um kit de modelos tridimensionais de apoio às aulas de biologia, ambos com abordagem tátil. Estes projetos foram definidos a partir de encontros com as respectivas professoras que indicaram que campos eram especialmente difíceis de ensinar sem a existência de material especialmente produzido com este fim.

Também foi realizada uma oficina de cotação de histórias com uma turma do Ensino Elementar 1 e a partir disso discentes e docentes do projeto e do IBC, escreveram uma história em conjunto que é a base de um livro que está sendo produzido. Cabe destacar que este processo de criação coletiva foi muito importante para aumentar a conscientização dos discentes da UFRJ em relação ao seu papel social do design e da universidade.

Todo material produzido, é avaliado continuamente pelas professoras orientadoras, autoras deste artigo e pela Professora Patrícia Ignacio Rosa (IBC). Os protótipos dos objetos voltados para uso em sala de aula serão encaminhados para revisão com os revisores cegos do Instituto, seguida de testagem com as crianças para posteriormente serem produzidos em maior escala.

\section{Pesquisa, processos e encaminhamentos}

Descrevemos aqui algumas considerações resultantes de nossas investigações sobre técnicas, recursos e aspectos perceptivos de nosso público alvo que orientam os aspectos projetuais e de produção dos objetos que desenvolvemos no projeto.

Foram identificados e analisados os tipos de publicações existentes no mercado e avaliamos as vantagens e desvantagens de cada um deles. Deparamo-nos, então, com os seguintes formatos: sistema Braille, audiolivros em formato MP3, áudio descrição em formatos MP3, SAP e ao vivo e livro Digital Daisy. O sistema Braille é o único sistema de alfabetização para cegos, contribuindo para o desenvolvimento da linguagem oral e escrita e sendo por isso, fundamental para o processo de ensino e aprendizagem. Outra vantagem, seria a autonomia do indivíduo para produzir textos. Algumas desvantagens deste sistema seriam as grandes dimensões do livro impresso desta forma, a leitura em Braille pode ser cansativa e o alto custo de impressão. $O$ segundo formato, o audiolivro em formato MP3, reproduz a voz humana sintetizada e tem como principal vantagem o baixo custo de produção. Além disso, permite aplicação em diferentes suportes, tais como CDs, pendrives e sites, tornando a obra portátil e de fácil manuseio. Um dos aspectos negativos deste formato seria a frequente interpretação do texto por parte do narrador além de não permitir a autonomia na produção textual. O processo de áudio descrição permite gravações no formato MP3 e SAP além de poder ocorrer ao vivo. É muito utilizada para descrever ilustrações, cenas de cinema, teatro e programas de TV. Também tem a desvantagem das vozes que interpretam o texto durante a descrição assim como não permite a autonomia textual. Por último, o livro Digital Daisy (Digital Accessible Information System ou Sistema de Informação Digital Acessível), livro digital sonoro que possui a grande vantagem de ser gratuito. Trata-se de um software que permite vários níveis de ampliação de texto e audição de voz simultânea, pode ser disponibilizado em CD e atinge tanto o público cego quanto o de visão sub-normal. De aspectos negativos estão a não autonomia de produção textual, os arquivos em formato PDF necessitam de um software específico para sua leitura, o $D D$ Reader +, assim como de um computador ou um celular. O sistema é considerado confuso e a descrição por vezes monótona. 
Optamos em nossos projetos de livros pelo uso do sistema Braille devido à capacitação para a leitura e produção textual que ele permite. Dentre os sistemas analisados, o Braille é o único que permite ao cego o processo de alfabetização, gerando maior autonomia e estimulando o desenvolvimento da capacidade verbal e escrita. Tendo em vista o viés educativo e a nossa pretensão em contribuir para os processos de aprendizagem, julgamos que o uso do Braille seria o mais adequado. Além da impressão do texto em Braille, nossas produções também têm impressão em tinta, pois além da leitura por cegos, os livros também podem ser lidos por indivíduos com baixa visão e videntes, facilitando a integração entre amigos e familiares com diferentes graus de acuidade visual. Nestes casos, a leitura dos livros pode se tornar uma atividade que promove a socialização entre videntes e não videntes, um aspecto importante para nosso projeto.

Por meio das conversas com os técnicos da gráfica do IBC, ficaram estabelecidas algumas regras gerais para as impressões dos livros. Considerando o tamanho das células em Braille e o limite de formato do papel suportado pelas impressoras em Braille disponíveis no local, as impressões podem ter a largura máxima de $39 \mathrm{~cm}$. O papel deve ter a gramatura mínima de $140 \mathrm{~g} / \mathrm{m}^{2}$ para suportar a "perfuração" do Braille e deve ser considerado nos projetos o relevo no verso da página, provocado por este tipo de impressão. Também foi verificado que a impressão em Thermoform, possibilita a impressão de relevo mas seria importante investigar novas formas de reprodução de texturas e volumes.

Como pretendemos atingir o público de baixa visão verificamos que determinadas fontes, sem serifa, com dimensões a partir de 24 pontos e o contraste de cores entre figura e fundo são de fundamental importância para a percepção das impressões em tinta. De acordo com o princípio da pregnância da forma, apresentada pela Teoria da Gestalt, formas simples, claras, com alto contraste entre figura e fundo são mais facilmente visualizadas.

Foram analisados livros voltados para nosso público alvo encontrados no mercado considerando como se dá a leitura tanto de texto quanto de imagens ou representações e de transposições para o meio tátil de imagens por indivíduos não videntes. Identificamos alguns padrões recorrentes que dificultam ou impossibilitam a leitura de texto e imagens nestas publicações e que evitamos reproduzir em nossos projetos.

É bastante comum encontrar livros para não videntes com capas projetadas como se fossem para videntes, sem informações em Braille. Nestes casos, a pessoa cega depende de alguém para identificar o livro ou CD que ela quer ler ou ouvir. Em relação aos desenhos táteis é frequente o uso de pontos em relevo para identificar contornos de figuras, que podem ser confundidos com os pontos do Braille pelos cegos. Também foram encontrados relevos ilustrativos, sem tridimensionalidade, o que torna impossível a identificação da figura pela pessoa cega. E por último, um padrão bastante recorrente, é o uso de elementos que são indicadores visuais como representativos que algo que não the corresponde. Como exemplo, o uso de algodão para representar uma nuvem, elementos que visualmente se parecem mas com sensações táteis bastante distintas.

No caso das imagens ou desenhos táteis, foi observada apenas a transposição do sistema de leitura visual e não uma adaptação efetiva à realidade perceptiva dos cegos. Esta prática recorrente, pode ser entendida como uma "colonização pelo visual", segundo destacam Hatwell e MartinezSarocchi (2000, p. 277, apud VALENTE, 2008, p.1)

A reivindicação de um colonialismo visual com relação à produção de desenhos táteis para 
cegos significa considerar que a inserção deste no contexto da não visualidade visa à imposição de códigos de uma realidade perceptiva dominante. Solicitar que pessoas cegas compreendam desenhos táteis seria, então, tentar adaptá-las a uma regra estabelecida, conduzí-los ao que se entende "normalidade". (VALENTE, 2008, p. 1).

Em nosso projeto, criamos objetos adequados à realidade perceptiva de nosso público alvo, procurando não reproduzir essas práticas buscando, portanto, produzir imagens, desenhos e texturas que se adaptem às necessidades de nossos leitores e não forçando-os a se adaptarem ao que é considerado normal ou adequado. Decidimos então trabalhar em nossos projetos com o design sensorial conceitual de forma a ampliar o universo lúdico da leitura, tornando-os sensorialmente sedutores. O objetivo é explorar todos os sentidos de forma a despertar a sensorialidade no relacionamento com o artefato.

O que buscamos provocar é a experiência estética e não uma transposição de imagens visuais para outros códigos comunicacionais. Não temos interesse em descrever as imagens ou impor sistemas de compreensão formais típicos da visão para o nosso público, queremos sim, despertar interesses, associações e vivências que possam despertar afeições.

A fabulação criadora nada tem haver com uma lembrança mesmo amplificada, nem com um fantasma. (...) Trata-se de libertar a vida lá onde ela é prisioneira, ou de tentar faze-lo num combate interno. (DELEUZE, 2005,p.;222)

Nossa intenção é, portanto, libertar a criança cega das cobranças em relação à aquisição de comportamentos e atitudes típicos do vidente mas que não lhe comportam já que a constituição de seu intelecto, sensibilidade e captação das informações do mundo não passa pela visão. Além disso, pretendemos, com estes recursos, seduzir o público vidente - especialmente pais e irmãos que não leem Braille - para partilhar experiências a partir de outros canais perceptivos. Pretendemos com isso que o leitor tenha uma leitura diferenciada daquela que já está habituado, agregando valores culturais através do Design.

\section{Projetos desenvolvidos e em desenvolvimento}

Em seguida apresentamos os projetos dos alunos do curso de Comunicação Visual - Design, desenvolvidos no âmbito do projeto Pleno Sentido, sendo os dois primeiros já concluídos e os restantes em desenvolvimento.

\subsection{A busca do sensível: abordagem diferenciada para a interação entre cegos e videntes no processo educativo através do design gráfico}

Uma adaptação do texto "Os bonecos de Barro", do livro "O Lustre" de Clarice Lispector, foi a escolha para o trabalho de conclusão de curso de Camille Xavier. Este texto, onde a autora coloca em foco $o$ inconsciente na literatura através do universo interior de seus personagens, se transformou em um livro de 23 páginas de texto impresso em Braille e tinta mais 23 páginas de texturas. A encadernação artesanal, com folhas soltas, foi pensada de modo a unir folhas soltas com diferentes texturas e volumes, onde fosse possível o livre manuseio das páginas mas sem perda da sequência de texto, conduzindo tanto a leitura textual quanto a sensorial.

As texturas desenvolvidas para este livro atendem aos seguintes princípios: estímulo da interação com o objeto livro, design com abordagem tanto sensorial quanto emocional (trabalhando a questão da memória afetiva), emprego de texturas abstratas e trabalho com os materiais essenciais destacados pelo texto. Além disso, foram trabalhadas ilustrações táteis lúdicas, oferecendo informação subjetiva, transmitindo as sensações do texto, com formas simples e de 
modo a oferecer o prazer da leitura através do toque.

Figura 1 - Livro encadernado e exemplos de folhas soltas

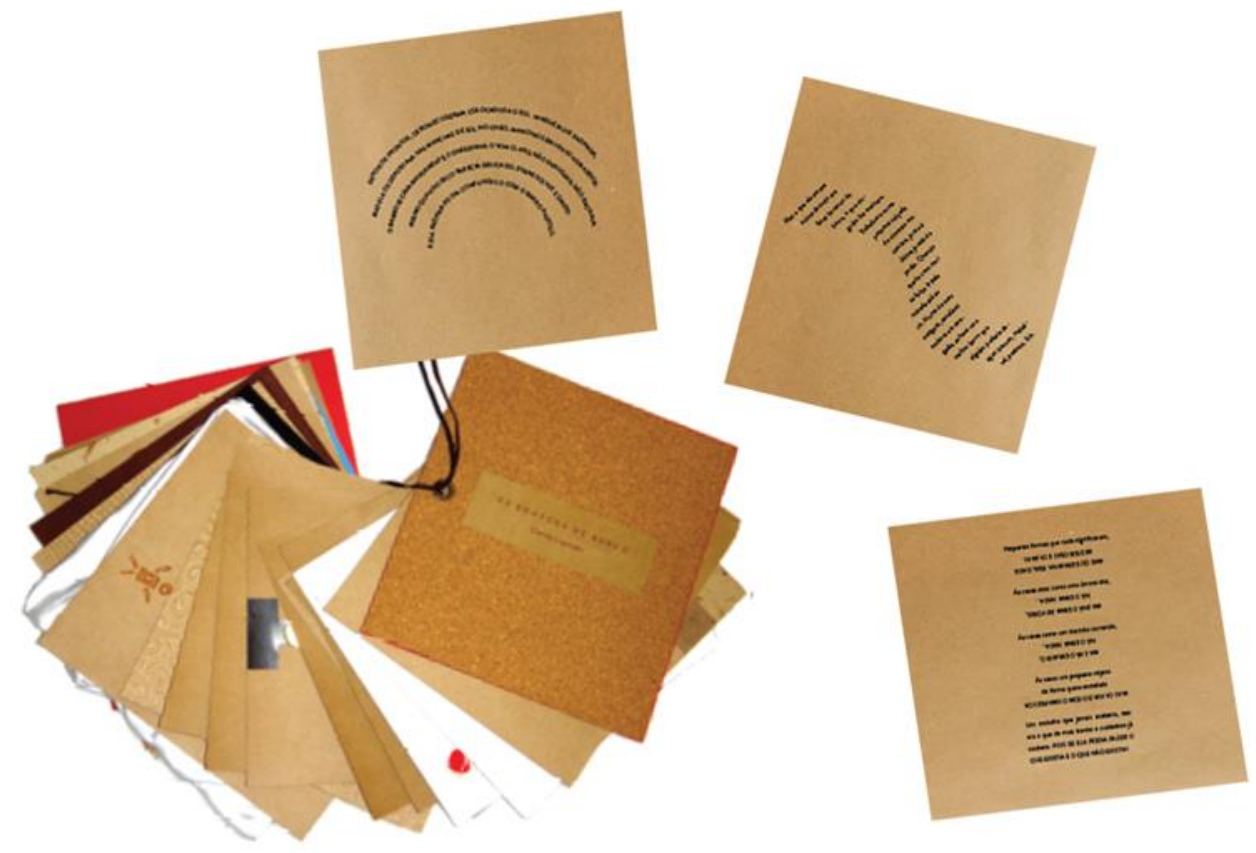

Fonte: Arquivo Pleno Sentido

Considerando o tamanho das células de Braille, o tamanho do texto para leitura por pessoas com visão subnormal e o limite de formato suportado pelas impressoras em Braille disponíveis no IBC, o livro apresenta formato de $29 \times 32 \mathrm{~cm}$. A transcrição do texto para o Braille foi feita através do programa Braille Fácil ${ }^{5}$. A diagramação do texto em tinta, com formato não convencional, busca explorar a forma do texto de acordo com as sensações relatadas pelo autor. Visa ainda permitir a interatividade e aproximar o leitor da subjetividade do personagem. Foi escolhida uma fonte sem serifa, de desenho simples e de boa legibilidade: Brandon Grotesque, no corpo $24^{6}$.

A identidade visual sem excessos explora tons terrosos, texturas naturais, orgânicas e rústicas de forma a dar subsídios materiais ao texto. O processo de criação do protótipo foi artesanal e empírico. A capa foi feita em cortiça e o miolo em papel Kraft para remeter a terra, ter toque rústico e diferenciado do papel normalmente empregado em publicações em Braille.

\subsection{Aura e as relíquias mágicas: uma coleção de livros infantis táteis impressos em Braille e em tinta}

Este segundo trabalho, também uma orientação de Trabalho de Conclusão de Curso, foi realizado por Carine Ferreira. A aluna redigiu sua própria história que descreve 4 reinos: o do ar, o da água, o da terra e o do fogo, cada um deles apresentado em um livro. O projeto se propõe a explorar o universo sensorial da criança cega e com visão subnormal de modo a trazer inserção dentro do espaço, tanto real quanto lúdico e imaginativo. A ideia deste conjunto de livros-

\footnotetext{
${ }^{5}$ O programa Braille Fácil, permite que um texto digitado, possa ser visualizado em Braille e impresso em Braille ou em tinta (inclusive a transcrição Braille para tinta). O programa é distribuído gratuitamente.

${ }^{6}$ Para este projeto devem ser utilizadas sempre fontes de fácil leitura.
} 


\section{Artigo Completo}

brinquedos é de criar uma história onde a criança siga a protagonista pelo seu jardim físico e imaginário convocando-o a partilhar de experiências sensoriais que são induzidas pelos 4 elementos da natureza. Assim os campos imaginativos e físicos se cruzam ampliando a percepção espacial da criança.

Figura 2 - Páginas dos livros do Reino do ar e Reino da água

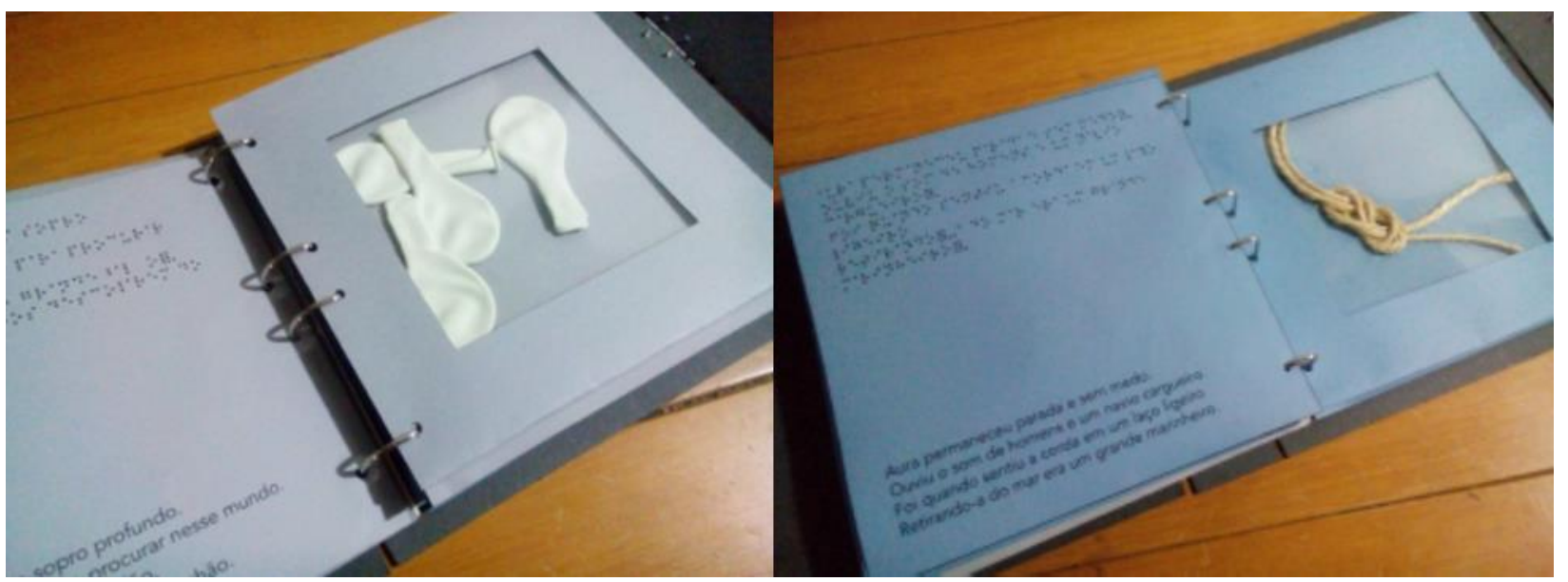

Fonte: Arquivo Pleno Sentido

Os recursos táteis são explorados de forma a reproduzir as provocações lançadas pelo texto bem como a atender seus desafios. No livro do Reino do ar, balões estimulam a criança a soprar e a soltar o ar para dentro e para fora do balão e um envelope com vários tipos de plumas, sugerem a diversidade de nossos pássaros. No Reino da água de páginas azul claro, gel revestido representa a maleabilidade da água e sua frieza emoliente e um laço de marinheiro mostra a corda que permite ao marinheiro salvar a personagem. No Reino da terra apresentam-se texturas de terra e flores secas e no último livro, o Reino do fogo, de páginas na cor laranja, surgem gotas de cera derretida que sugerem que sejam descascadas e bastões de carvão demonstram a capacidade de combustão do fogo.

Todo o projeto gráfico, incluindo embalagem, capa, páginas de texto, envelopes sensoriais e relíquias foram pensados para promover uma rica experiência sensorial. A montagem do produto foi basicamente artesanal e a impressão em Braille realizada em uma máquina Perquins ${ }^{7}$. Em termos de diagramação, as páginas foram divididas horizontalmente sendo o texto em Braille posicionado na parte superior e o mesmo texto replicado em tinta na parte inferior na fonte Avenir em corpo 24 para favorecer a leitura para pessoas de baixa visão. Cabe destacar neste projeto o fato do conjunto de livros ter sido pensado com páginas agregadas por elos como num fichário. Tal formato visa a livre manipulação das páginas e encartes pela criança. ${ }^{8}$ As relíquias conquistadas pela criança após a leitura de cada livro foram desenvolvidas em tecnologia de impressão 3D. Para embalar o conjunto, os livros e as relíquias foram acondicionadas em sacola de tecido.

\footnotetext{
${ }^{7}$ Perquins é um tipo de máquina de escrever especialmente desenvolvida para escrita em Braille.

${ }^{8}$ As crianças cegas e de baixa visão são alfabetizadas em diferentes idades dependendo de suas capacidades, idade em que passam a ser assistidas no IBC, entre outros fatores avaliados pela instituição. Em função deste fato produzimos materiais voltados para a fase de aprendizagem na qual as crianças estão inseridas, neste caso o Ensino Fundamental I, e não sua faixa etária.
} 


\subsection{Desenvolvimento de kit de complementação pedagógica para crianças deficientes visuais utilizando a tecnologia de impressão 3D}

Neste Trabalho de Conclusão de Curso a graduanda lana Alves se propôs a utilizar novas tecnologias na resolução de problemas de acessibilidade e melhoria da qualidade de vida da criança deficiente visual, de forma à facilitar o acesso à informação. Neste projeto aliam-se novas tecnologias e meios de produção digitais ao Design e à experiência do usuário na criação de modelos que auxiliem no ensino da Biologia, oferecendo aos professores novos recursos que visam melhorar a absorção de conteúdo por parte das crianças.

Figura 3: Desenho de esqueleto de sapo realizado em software 3D e modelo de polífero
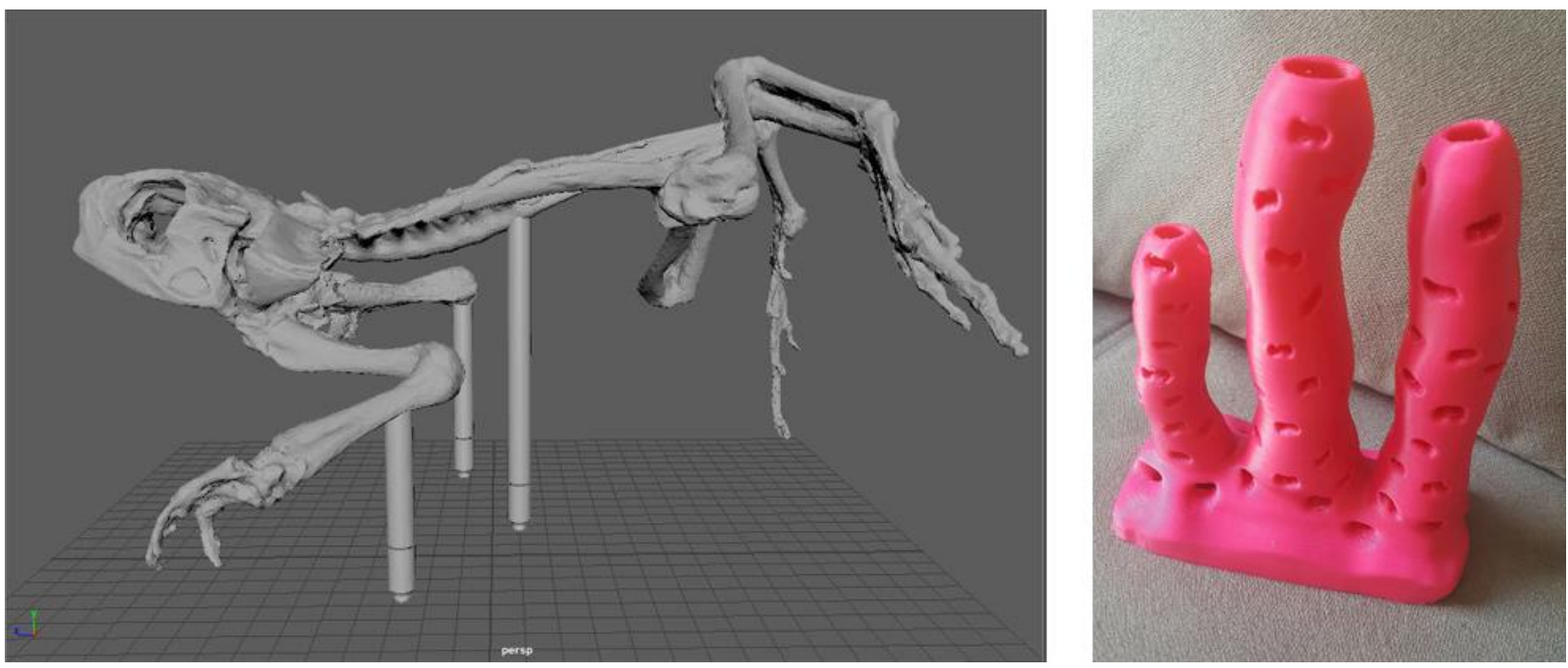

Fonte: Arquivo Pleno Sentido

Este projeto, atualmente em fase de conclusão, foi pensado a partir das demandas apresentadas pelos professores do IBC visando contribuir para melhorar a escassez de recursos didáticos disponíveis no mercado. Inicialmente, foram desenvolvidos estudos em torno do desenvolvimento cognitivo e da recepção e interpretação da informação pela criança cega e da importância da exploração dos sentidos para a aquisição de conceitos. Seguindo essa linha, estão sendo desenvolvidos objetos que estimulam a aprendizagem tátil-cinestésica, isto é, a aprendizagem que acontece através do uso do tato.

No ensino da Biologia, alunos com deficiência visual, não têm acesso a importantes recursos didáticos visuais tais como tabelas, desenhos, gráficos, que ajudam a tornam a disciplina menos abstrata. Para alunos com deficiência visual, materiais didáticos que explorem recursos táteis são de grande importância para facilitar o entendimento da disciplina e favorecer a aprendizagem, ajudando a motivar estes alunos.

A professora de Biologia apresentou o livro didático que utiliza em sala de aula para a aluna indicando alguns temas com os quais tinha especial dificuldade em trabalhar sem apoio paradidático. lana escolheu dentro das possibilidades apontadas 3 temas de estudo: um fóssil, um porífero e uma planária. 
No caso do fóssil foi criado o esqueleto de um sapo que ficará acondicionado em uma caixa de areia mantido estável por um suporte especialmente desenhado para este fim. A criança entrará em contato pelo tato com o objeto buscando-o dentro da caixa de areia e entendendo assim os processos de fossilização. No caso do polífero foi produzido um modelo, vazado que será disposto dentro de um aquário de acrílico com uma pequena bomba de aquário em seu interior. 0 modelo possui aberturas que permitem a saída da agua reproduzindo o sistema de funcionamento do polífero. A planária ainda está em fase de desenvolvimento.

Neste projeto, os primeiros esboços realizados foram revisados pelos professores do IBC antes de serem impressos em 3D e apresentados para as crianças. A modelagem realizada no software $3 D^{9}$ deu origem a protótipos de baixa fidelidade e neste momento os modelos do esqueleto sapo e do polífero estão em fase de testagem com as crianças para observação de sua efetividade. Após a análise dos resultados e feedback dos professores, se necessário serão feitos ajustes e finalmente impressos novos modelos.

\section{4 "O chinelo da mamãe": livro grafo-tátil para crianças cegas e de baixa visão}

O projeto das bolsistas de extensão Fátima de Abreu e Anna Beatriz Accioly consiste na criação de um livro-objeto com uma história feita por e para crianças com deficiência visual acompanhado de objetos que remontam à temática "praia".

A história foi desenvolvida a partir da participação das alunas em oficinas de contação de histórias para as crianças do IBC. Neste caso houve participação direta das crianças tanto no argumento, a perda de um chinelo na praia, quanto no desenvolvimento da história, supervisionadas pelos professores do IBC e da UFRJ. Deste modo, foi criado um cenário de aventura que empodera e encoraja a criança com deficiência a explorar lugares e a viver novas experiências e especialmente ressaltar sua capacidade de criação de conteúdo. O livro traz a história de uma criança cega e suas experiências sensoriais vividas em um dia na praia, suas aventuras e descobertas. Neste projeto pretende-se trabalhar com elementos do cotidiano das crianças e integralizar a aprendizagem tanto pelos procedimentos encampados pela metodologia de ensino de Paulo Freire ${ }^{10}$ quanto pela articulação com atividade proporcionada pelo Instituto que consiste em passeios à praia próxima ao IBC. De modo lúdico, este livro poderá ser um facilitador na educação básica da criança portadora de deficiência visual.

Assim como os outros livros produzidos pelo Pleno Sentido (descritos nos itens 4.1 e 4.2), este também poderá ser lido por videntes e pessoas com baixa visão, por isso, além do Braille, o texto também será impresso em tinta e com tipografia em corpo ampliado. Nas páginas do livro serão explorados outros sentidos através de peças texturizadas e sons que estimulem a relação lúdica da leitura e algumas ilustrações de poucos traços, simplificados mas em alto contraste para permitir a visualização pelas crianças com baixa visão. Para estas crianças é recomendado o uso de um suporte a 45 graus de inclinação para apoio do livro, por isso é parte do projeto, uma embalagem que funcionará como apoio e acondicionará o livro e objetos, facilitando o transporte.

\footnotetext{
${ }^{9}$ Softwares 3D são programas de computador que permitem a construção de modelos em três dimensões de forma a viabilizar sua posterior impressão em impressoras especiais para este tipo de trabalho.

${ }^{10}$ Em especial as obras Educação como prática da liberdade, Rio de Janeiro: Paz e Terra, 1989 e Pedagogia do oprimido, New York: Herder \& Herder, 1970.
} 

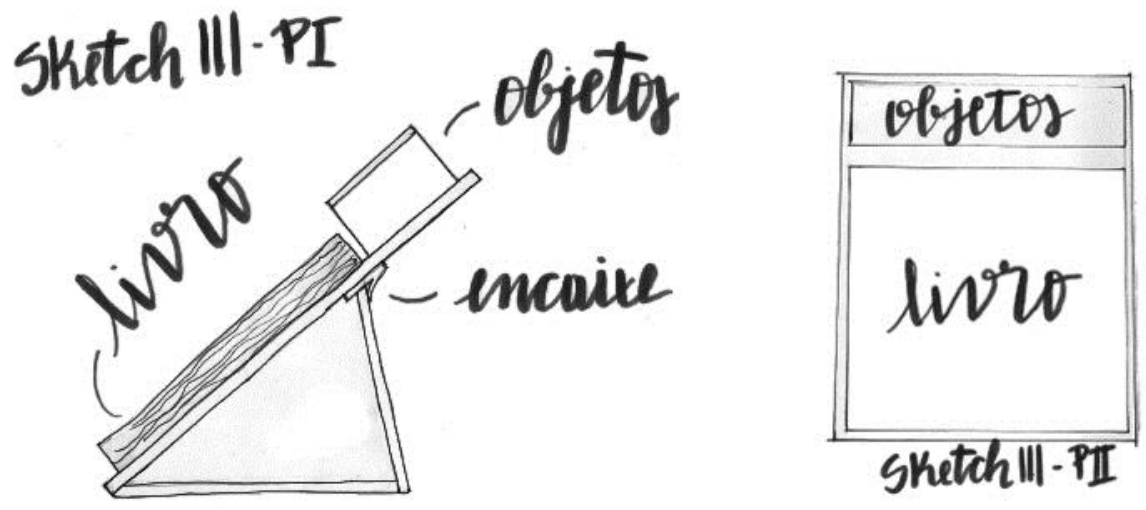

Fonte: Arquivo Pleno Sentido

\subsection{Adaptação do jogo Batalha Naval para crianças não-videntes e com baixa visão}

O projeto de Laise dos Anjos e Luiza Eiras (bolsista de extensão) tem o objetivo de auxiliar o estudo das coordenadas cartesianas. A motivação para a adaptação do jogo surgiu a partir da entrada em sala de aula das alunas, que buscavam verificar as demandas e lacunas existentes relativas aos materiais didáticos e lúdicos. Em uma das turmas de matemática, a professora do IBC destacou a importância do jogo batalha naval como auxílio no ensino da disciplina, especialmente para o entendimento da noção de coordenadas, dos eixos $\mathrm{x}$ e $\mathrm{y}$. Este projeto consiste no desenvolvimento de uma versão adaptada do jogo para que seja usado tanto como material de apoio em sala de aula quanto como um jogo para entretenimento, no qual será possível integrar jogadores com perdas visuais e jogadores videntes.

Nesta adaptação as regras do jogo são mantidas, sendo possível jogar como na versão original. Os materiais e texturas utilizados, os espaçamentos dos tabuleiros e formato das peças foram definidos de modo que sejam agradáveis ao toque para os não-videntes. O Braille é utilizado para indicar letras e números, as divisões nas linhas da grelha do tabuleiro são alto relevo, o encaixe das peças se dá através de seus pinos e furos no tabuleiro utilizando os espaços internos das divisões da grelha, as peças que correspondem aos barcos possuem formas e texturas diferenciadas assim como cores bem contrastes. Um espaço do tabuleiro se destina a um ábaco simples de dezenas e de unidades, para auxiliar a contagem de pontos e sob o tabuleiro, existe um espaço para guardar as peças do jogo. A grelha é feita com MDF e os barcos em resina, o protótipo está sendo desenvolvido e em seguida será testado com as crianças em sala de aula. 
Figura 5: Protótipo do tabuleiro para o jogo Batalha Naval

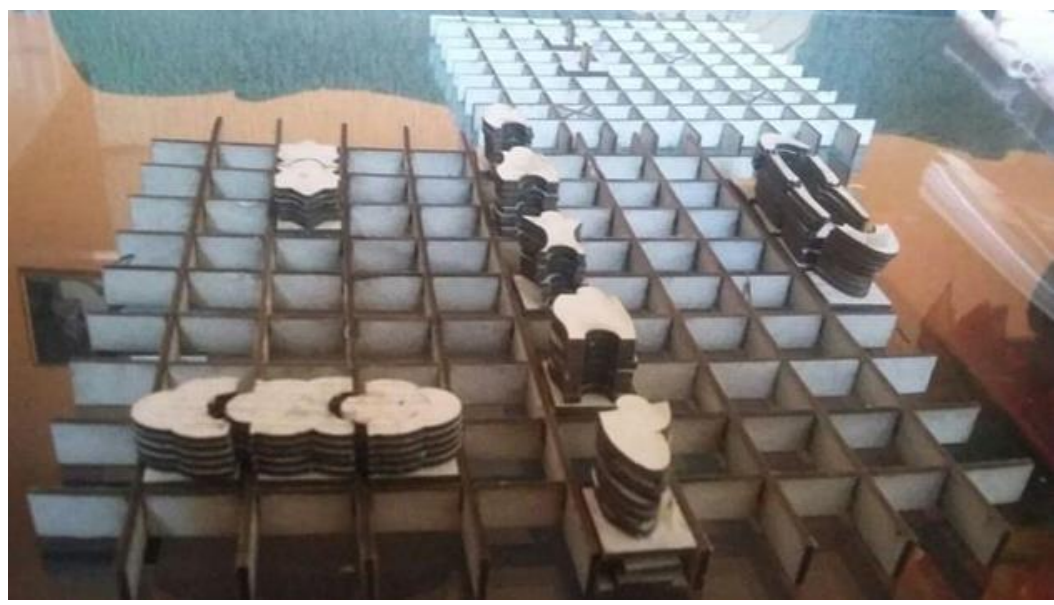

Fonte: Arquivo Pleno Sentido

\section{Considerações finais}

O estudo aqui apresentado revela nossa incursão no campo da criação de material grafotátil para crianças cegas e de baixa visão. A experiência que envolve professores do IBC, da UFRJ, e alunos de ambas as instituições tem sido extremamente produtiva. Consideramos fundamental a contribuição do campo do Design, através da instrumentalização de alunos, futuros profissionais para realizar um trabalho inclusivo. Neste caso, nosso projeto pretende realizar um trabalho de inclusão social, através de objetos pensados para promover a interação tanto entre indivíduos com deficiência visual quanto destes e seus familiares, amigos e colegas. Através dos objetos lúdicos voltados para o suporte didático, pretende-se contribuir com um estímulo no processo de aprendizado.

\section{Referências bibliográficas}

BARRAGA, N.C. Necesidades de aprendizaje de los niños discapacitados visuales (trad. S.E. Crespo "Learning needs of visually handicapped children" (original no publicado). In: Discapacidad visual, ICEVH. Córdoba, Argentina, №46 Núm. 16, p.161-210, 1986

CERQUEIRA, J.B.; FERREIRA, E.M.B. Recursos didáticos na educação especial. Rev. Benjamin Constant, Rio de Janeiro, n. 5, p. 1-6, 1996.

DELEUZE, G e Felix Guattari. O que é filosofia? São Paulo: Editora 34, 2005

FREIRE, Paulo. Educação como prática da liberdade. Rio de Janeiro: Paz e Terra, 1989

. Pedagogia do oprimido. New York: Herder \& Herder, 1970.

GIBSON, E.J. Principles of Perceptual Learning and Development. New York : Appleton-CenturyCrofts, 1969.

MARKS, Laura $U$. The skin of the film. Intercultural cinema, embodiment, and the senses. USA: Duke University Press, 2000.

MARTIN, M. B.; BUENO, S. T.; Deficiência visual: aspectos psicoevolutivos e educativos. 1ạed. São Paulo: Santos, 2003. 


\section{Artigo Completo}

VALENTE, D. Imagens que comunicam aos dedos: a fabricação de desenhos táteis para pessoas cegas. In: Anais do $17^{\circ}$ Encontro Nacional da Associação Nacional de Pesquisadores em Artes Plásticas - Panorama da Pesquisa em Artes Visuais, 2008. 